\title{
Evaluation of All-Round Modular Scaffolding (ARMS) type Scaffold by using BS1139 Standards for Industries
}

\author{
M.S. Yob ${ }^{1,2^{*}}$, N.A. Mat Tahir ${ }^{2}$, M.J. Abd Latif ${ }^{1,2}$, M.F. Mohd Hassim ${ }^{3}$, Z. Jamil ${ }^{3}$ \\ ${ }^{1}$ Advanced Manufacturing Centre (AMC), \\ Universiti Teknikal Malaysia Melaka, Hang Tuah Jaya, 76100 Durian Tunggal, Melaka, MALAYSIA \\ ${ }^{2}$ Faculty of Mechanical Engineering, \\ Universiti Teknikal Malaysia Melaka, Hang Tuah Jaya, 76100 Durian Tunggal, Melaka, MALAYSIA
}

${ }^{3}$ HRSB Holdings Sdn. Bhd., Lot 2044 Mukim Sungai Baru Ulu Solok Duku, 78300 Masjid Tanah, Melaka, MALAYSIA

*Corresponding Author

DOI: https://doi.org/10.30880/jamea.2021.02.01.006

Received 25 May 2021; Accepted 23 June 2021; Available online 02 August 2021

\begin{abstract}
Scaffolds can be categorised into access scaffolds and support scaffolds based on its functions: access scaffolds and support scaffolds. Regardless, both are only consent to be used when it follows requirement set forth by the government in order to protect the workers' safety and health. Due to increased demand for scaffolds manufacturers try to compete with each other by developing various type and sizes of scaffolds. Unfortunately, the usage of these modern scaffolds such as All-Round Modular Scaffoldings are rather limited due to its deviations from the BS 1139 standards. This study aims to determine the distribution force on the All-Round Modular Scaffolding determine its suitable duty category based on the BS1139 guidelines. Standard parts of ARMS from manufacturer was used to build one storey x 1 bay (sizing $3 \mathrm{~m} \mathrm{x} 3 \mathrm{~m}$ ) structure and was assembled by authorised and professional contractor. The structure was then put through load test. The load was placed on top of the working platform and the deflection of the components was measured. The findings reveal that the structure as well as the individual platform can support loads up to $500 \mathrm{~kg}$ with no crack or permanent deformation observed after the test. By referring the BS1139 standards, the All-Round Modular Scaffolding is surpassing the requirement for general and heavy-duty scaffold with distributed load on platform recorded to be $2.67 \mathrm{kN} / \mathrm{m}^{2}$ and concluded that the additional length of the components does not compromise the working purpose of the scaffolds.
\end{abstract}

Keywords: Scaffolding, load test, deformation

\section{Introduction}

Scaffolds are generally temporary structures mainly used in construction to support loads, including humans, equipment, and work material. Scaffolds can be categorized into two types depending on their purpose: access scaffolds and support scaffolds. Access scaffolds are used to support light to moderate tools and usually attached to work buildings. Support scaffolds are scaffolding that support concrete or construction base. This type of scaffold is designed to support heavy loads [1,2].

Scaffolds are typically built of slender members composed of high-strength cold-formed steel tubes. Manufacturers, on the other hand, have slightly varying configurations of scaffold components (units). Regardless, the components shared the same characteristics. Scaffolds components are basically consisting of vertical members, horizontal members, and braces [3,4]. Figure 1 shows the basic parts (components) of scaffold. 


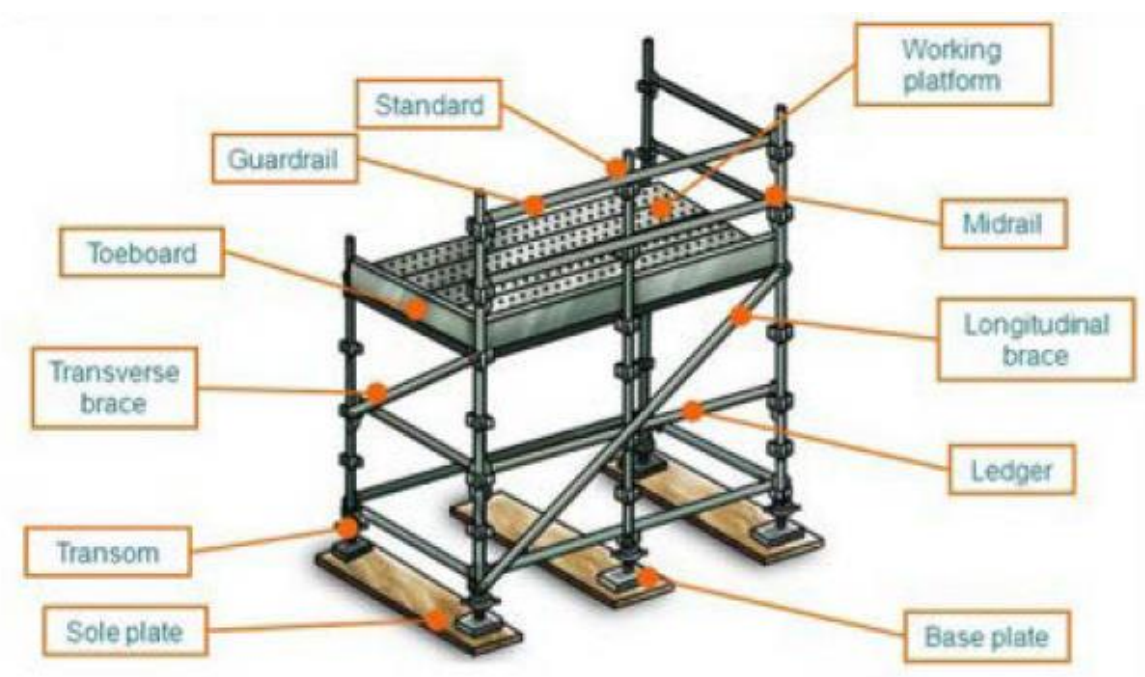

Fig. 1 - Basic parts of scaffold [5]

Scaffolds can be used from one level (lift) up to many and can be built to many bays and rows depending on its need. The height of a single lift is usually between $1-2.5 \mathrm{~m}$; meanwhile, the bay could be sized between $0.7-2.5 \mathrm{~m}$ [3]. Due to their assembly flexibility, the scaffolding system can be built in various shapes to meet the work areas and geometries.

For light use, aluminium is widely used nowadays due to its light behaviour compared to steel. Interestingly, bamboo and timber has been used as scaffolding in several countries in Asia since the past until today [5,6]. However, this natural plant is unable to be reassembled and reused as many as steel and aluminium scaffold. Maintaining the integrity and strength of bamboo is also more challenging as each tree might possess different behaviour depending on its growth area and environment. Moreover, since scaffolds structures are flexible as prefabricated and assembled tailored to the working geometries and conditions, the components are reusable from one job to another. Thus, the components sometimes possessed imperfection(s) and might jeopardise the structural integrity [4,5,7-11].

Besides imperfections that occur due to repetitive use, their other factor that was causing failures and jeopardise the safety of operators and others such as overload usage, unstable structure, obstruction during operation and human error $[1,3,4,8,11-13]$. Therefore, overload and unstable structure are classified as the main contributor to the failure of the scaffold structure. Furthermore, as the scaffolds are susceptible to the load more that the materials can handle, bolts holding the structure with building may crack and rupture, while the vertical member will present with buckling before break $[4,8,10,11,13-15]$.

Buckling typically occurs at the beginning of the failure before the structure collapsed. For a single lift and bay, buckling is easier to notice than a larger structure; hence, it is relatively hard to notice buckling signs during operations. Sometimes, the yield and strength of a structure are differs compared to one single component. Thus, the researcher suggested that computer-aided software such as Finite Element Analysis and experimental study called load test can be used to determine the deformation of structure to project the factor safety of a structure or component [11,15-17].

In order to reduce the failures and fatalities, there are regulations provided by the authorities to be followed by the contractors. Many research focused on assessing the risk, safety, and health involving the scaffolding works [15,18-20]. Standards developed by regulated bodies such as British Standard (BS) since previous decades act as guidelines and highlight the requirements for material, acceptable loads, and factor safety. For scaffolding, standards such as BS 1139 was developed under the direction of the Civil Engineering and Building Structures Standards Policy Committee. The BS 1139 standard is part of series specifying requirements for designing, constructing, and testing equipment for use in scaffolding and other temporary structures [22]. These guidelines have been referred throughout the world to maintain the safety and health of the workers and related parties.

In Malaysia, Construction Industry Development Board (CIDB) is the Government Agency entrusted to enforce the Malaysia Standard mandated on the importation of construction products listed under the Customs (Prohibition of Imports) Order 1998 Amendments 2003, 2004 \& 2009 through the issuance of Certification of Approval (COA). Therefore, the scaffolding design shall comply with several standards and acts such as MS 1642 - Part 1 to 5 and Factory and Machinery Act 1967 (Act 139 - Scaffolds). Based on the act provided, the factor safety for scaffolding is 4.0 [2126].

The Department of Occupational Safety and Health (DOSH) has regulated the standards requirement for the usage of scaffolds. This regulation referred to the BS 1139 Standards, where the minimum imposed loads of the scaffolds will determine the type of duty of the scaffolds. Table 1 shows the service loads for the working platform based on BS 1139 - Part 5: 1990. 
Table 1 - Service loads for working platform [5]

\begin{tabular}{ccc}
\hline \multicolumn{1}{c}{ Minimum Imposed Loads } \\
\hline $\begin{array}{c}\text { Duty } \\
\begin{array}{c}\text { Inspection and } \\
\text { Lery light duty }\end{array}\end{array}$ & $\begin{array}{c}\text { Inspection, painting, stone cleaning, light } \\
\text { cleaning and access }\end{array}$ & $\begin{array}{c}\text { Distributed Load } \\
\text { on Platform }\end{array}$ \\
$\begin{array}{c}\text { General- } \\
\text { purpose }\end{array}$ & $\begin{array}{c}\text { A general building including brickwork, } \\
\text { pointing }\end{array}$ & $0.75 \mathrm{kN} / \mathrm{m}^{2}$ \\
$\begin{array}{c}\text { plandow and mullion, fixing, rendering, } \\
\text { plastering }\end{array}$ & $2.00 \mathrm{kN} / \mathrm{m}^{2}$ \\
$\begin{array}{c}\text { Heavy duty } \\
\text { Masonry or } \\
\text { special duty }\end{array}$ & $\begin{array}{c}\text { Blockwork, brickwork, heavy cladding } \\
\text { Masonry work, concrete blockwork and very } \\
\text { heavy cladding }\end{array}$ & $2.50 \mathrm{kN} / \mathrm{m}^{2}$ \\
\hline
\end{tabular}

With the rise of construction industries, scaffolding manufacturers also scale up their products to compete. Therefore, besides providing stronger and sturdier components, a longer beam was also proposed (up to 3 m). However, the knowledge on scaffolding more significant than $2.5 \mathrm{~m}$ x $2.5 \mathrm{~m}$ is rather limited and unfamiliar yet. Thus, this study intends to determine the load distributed on the All-Round Modular Scaffolding (ARMS) of $3 \mathrm{~m}$ x $3 \mathrm{~m}$ by using load test on the assembled single bay-one story structure and on one unique platform to determine the distributed load and its suitable type of duty.

\section{Methodology}

In this study, the scaffolds structure tested was already build by a reliable and professional contractor. The type of scaffold used is steel All-Round Modular Scaffolding sizing $3 \mathrm{~m}$ x $3 \mathrm{~m}$. ARMS is an industrial standard for modular scaffolding, which has to surpass the standard conventional scaffolding. ARMS provides higher design flexibility and adaptability than traditional scaffold dies to its versatile locking and assembling mechanism. This type of scaffolding is vastly used nowadays, especially in power stations, refineries, plants, arenas, bridges.

The ARMS are bolt-fee, and it utilises ring lock ideas by having the rosette built on a vertical standard by sliding wedge head over the rosette holding the vertical and horizontal component together. A truss ledger was installed around sides under the standing platform with additional support of diagonal brace on all vertical components to support the structure. Table 2 shows the comparison between the ARMS and traditional tubular and coupler scaffolding given by the supplier.

Table 2 - Comparison between ARMS with traditional tubular and coupler scaffolding

\begin{tabular}{ccc}
\hline Type of Scaffolding & $\begin{array}{c}\text { All Round Modular } \\
\text { Scaffolding (ARMS) }\end{array}$ & $\begin{array}{c}\text { Tubular and Couplar based } \\
\text { on BS 1139 }\end{array}$ \\
\hline Outer Diameter (mm) & 48.30 & 48.30 \\
Wall thickness (mm) & 4.00 & 4.00 \\
Tensile Strength (N/mm $\left.{ }^{2}\right)$ & 527 & 449 \\
Yield Strength (N/mm $\left.{ }^{2}\right)$ & 452 & 402 \\
Positive Joints $(\mathrm{kN})$ & Rosette 22.72 & Double Clamp 6.25 \\
& & Swivel Clamp 6.25 \\
\hline
\end{tabular}

Figure 2 shows the ARMS build for the test. In order to assess the durability and distributed load on the platform, a load test was conducted. To collect the deflection of the structure, one dial gauge was installed at the bottom centre of the working platform, and two dial gauge was installed on vertical components (in $\mathrm{X}$ and $\mathrm{Y}$ direction). For individual platform assessment, only one dial gauge was installed at the centre of the platform. The dial gauges installations for the whole structure and individual platform are shown in Figure 3 and 4, respectively.

The deflection of the beam was recorded on every $100 \mathrm{~kg}$ and $20 \mathrm{~kg}$ load added for structure load test and individual platform test, respectively. The displacement recorded were then plotted against the load subjected. 


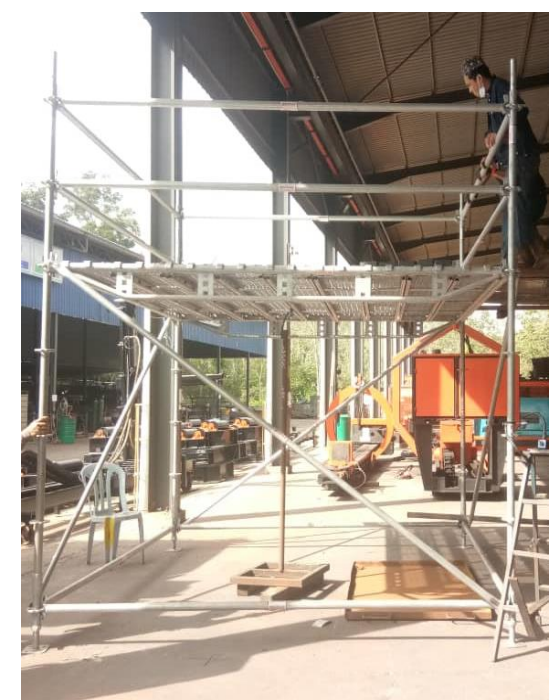

Fig. 2 - Single bay - one story of ARMS Scaffold built
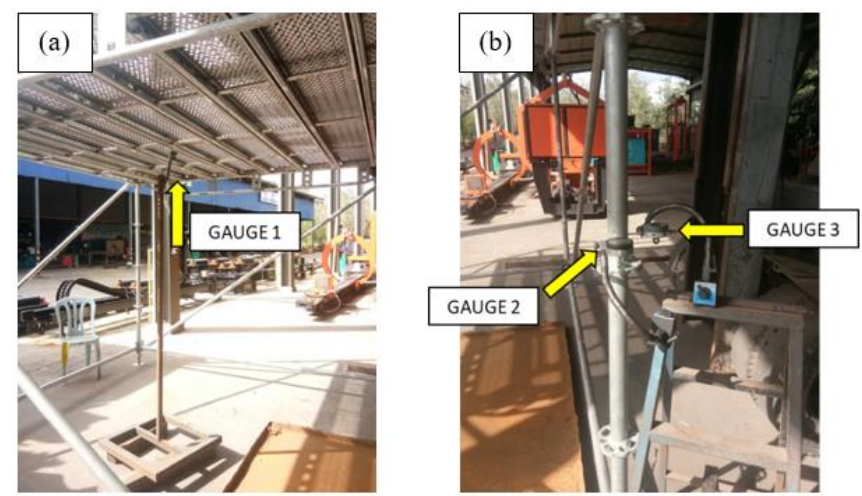

Fig. 3 - Dial gauge installation at (a) bottom centre; (b) vertical component of the structure

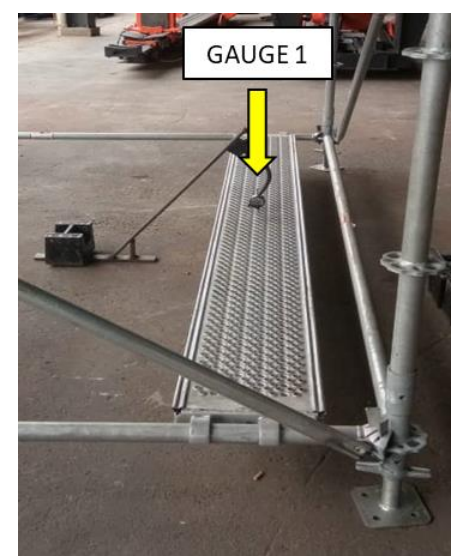

Fig. 4 - Dial gauge installation for individual platform

\section{Finding and Analysis}

The loading condition during the test are shown in Figure 5. The data collected during the whole structure and individual platform load test are plotted into a graph as shown in Figure 6 for the whole structure and individual platform.

The maximum deflection recorded for the whole structure test is $6.13 \mathrm{~mm}$ meanwhile, the individual test is 34.84 $\mathrm{mm}$. By referring to the BS 1139 - Part 5, clause 5.2.7 where "When subjected to the concentrated load specified in 5.2.3 the maximum deflection of any decking component shall not exceed 1/100 of the span of that decking component". However, the mentioned clause 5.2.3 explaining the "structure must support load for an area of $500 \mathrm{~mm} \times 500 \mathrm{~mm}$ ". It also explained that "when the platform contains any independent decking component less than $500 \mathrm{~mm}$ wide, the concentrated load shall be reduced for this component in proportion to the width" [22]. In this case, the platform size is $250 \mathrm{~mm}$ x $3000 \mathrm{~mm}$, where the maximum deflection for $250 \mathrm{~mm}$ x $250 \mathrm{~mm}$ should be $1.25 \mathrm{~mm}$ or less. 

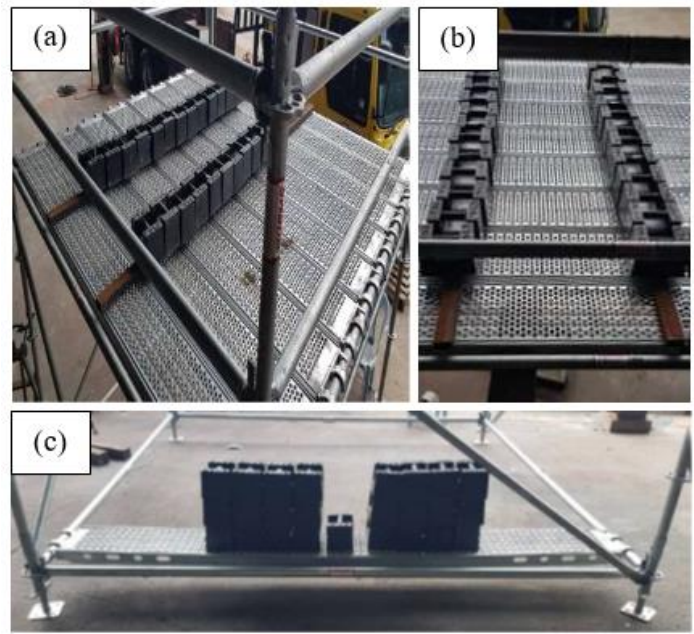

Fig. 5 - Actual loading conditions for (a) whole structure (isometric view); (b) whole structure (front view); (c) individual platform (front view)
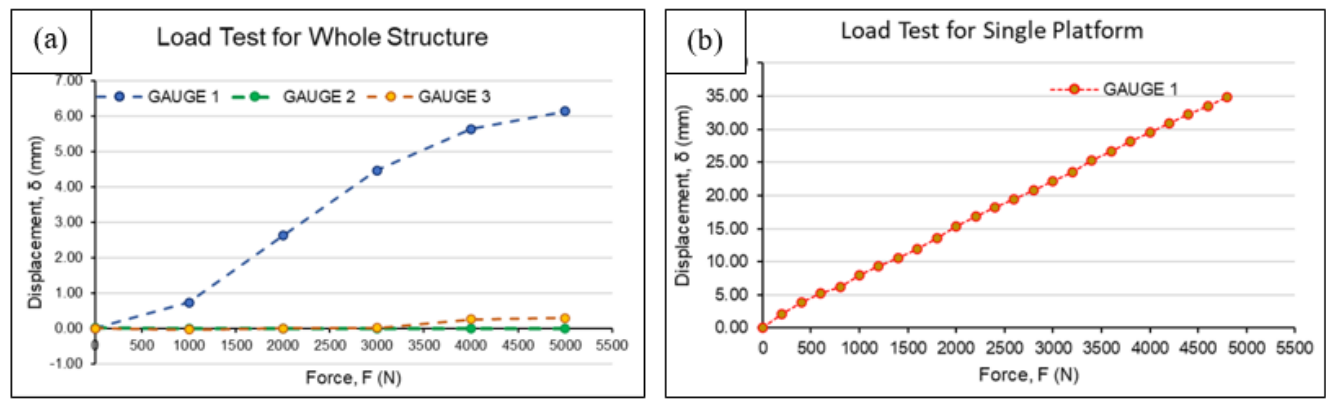

Fig. 6 - Dial gauges reading for (a) overall structure performance; (b) individual platform performance

From Figure 6, it can be seen that the components deflected as the load added. By looking closely at Figure 6, gauge 2 and 3 shows a small increment meanwhile gauge 1 shows a large increment as the force increases. The horizontal components that are perpendicular to the force show bending behaviour. It was the same behaviour observed on the individual platform in Figure 6. This is because both gauge 1 (whole structure and individual platform) received force perpendicular to the component's direction.

Unlike the horizontal components (platforms), the vertical components only show a slight deflection on $\mathrm{X}$ and $\mathrm{Y}$ directions. Since the force acting on the components is parallel to the component's direction, the component undergoes buckling. Assuming that the structure is perfectly straight, the force acting on the components was around $1250 \mathrm{~N}$ on each vertical column. Thus, resulting in a small deflection recorded.

As explained previously, by referring to clause 5.2.7 Part - 5 of BS 1130, the maximum acceptable deflection for the used platform area is equal or less than $1.25 \mathrm{~mm}$. Thus, for the tested platform, the maximum allowable deflection is $15 \mathrm{~mm}$. Projected from Figure 6 (b), the maximum acceptable load acting on the platform is approximately $2000 \mathrm{~N}$.

However, by analysing the deflection behaviour, the ARMS structure and components able to withstand up to 5000 $\mathrm{N}$ force without reaching the plastic deformation. Regardless, the deflection for both vertical and horizontal components was believed to be in the elastic region. This is because as the load removed from the structure and platform, the structure back to its original position. A visual inspection conducted after the test shows no signs of crack, bend, or wear.

To obtain the distribution load on the platform $\left(\mathrm{kN} / \mathrm{m}^{2}\right)$ was calculated as follows:

$$
\text { Distributed load on platform }\left(k N / m^{2}\right)=\frac{\text { Load } \times \text { Gravity }}{\text { Area }}
$$

Where Area is $0.75 \mathrm{~m}^{2}$, load applied is $200 \mathrm{~kg}$.

The distributed load on the platform for the ARMS structure are approximately $2.67 \mathrm{kN} / \mathrm{m}^{2}$. The distributed load on the platform is proven to surpass the requirement by DOSH (from Table 1) for service loads BS 1139 on General Purpose $\left(2 \mathrm{kN} / \mathrm{m}^{2}\right)$ and Heavy Duty $\left(2.5 \mathrm{kN} / \mathrm{m}^{2}\right)$ [5]. 


\section{Conclusion}

Based on the analysis, it can be concluded that the ARMS $3 \mathrm{~m}$ x $3 \mathrm{~m}$ structure is safe to be used as a heavy-duty platform by comparing it to DOSH standards on BS1139 scaffolds. However, dully noted that the findings only consider distributed load on platform and deformation with no other external factor such as moving loads or extreme conditions. Regardless, it is safe to say that the ARMS $3 \mathrm{~m}$ x $3 \mathrm{~m}$ is safe to be used under right compliance despite the size being slightly bigger than BS1139 traditional scaffolds.

\section{Acknowledgement}

The authors gratefully acknowledge HRSB Holdings Sdn. Bhd. for the resources access and use the pictures for this work. The authors would like to thank Applied Mechanical Design laboratory Universiti Teknikal Malaysia Melaka and Advanced Manufacturing Centre, Universiti Teknikal Malaysia Melaka, to support this study.

\section{References}

[1] E. Dogan, M. A. Yurdusev, S. A. Yildizel, and G. Calis, "Investigation of scaffolding accident in a construction site: A case study analysis,” Eng. Fail. Anal., vol. 120, pp. 1-13, 2021

[2] P. Pacheco, H. Coelho, P. Borges, and A. Guerra, "Technical challenges of large movable scaffolding systems," J. Int. Assoc. Bridg. Struct. Eng., vol. 21, no. 4, pp. 450-455, 2011

[3] T. Chandrangsu and K. J. R. Rasmussen, "Review of past research on scaffold systems," 2009.

[4] W. K. Yu, K. F. Chung, and S. L. Chan, "Structural instability of multi-storey door-type modular steel scaffolds," Eng. Struct., vol. 26, pp. 867-881, 2004

[5] Department of Occupational Safety and health Malaysia (DOSH), "Guidelines for Approval of Design Scaffolding," 2016

[6] T. Chandrangsu and K. J. R. Rasmussen, "Investigation of geometric imperfections and joint stiffness of support scaffold systems," J. Constr. Steel Res., vol. 67, pp. 576-584, 2011

[7] J. L. Peng, A. D. Pan, and W. F. Chen, "High clearance scaffold systems during construction - I. Structural modelling and modes of failure," Eng. Struct., vol. 18, no. 3, pp. 247-257, 1996

[8] M. Pieńko and E. Błazik-Borowa, "Experimental studies of ringlock scaffolding joint," J. Constr. Steel Res., vol. 173, pp. 1-13, 2020

[9] Z. Zhao, H. Liu, J. Dong, and Y. Bian, "Buckling Capacity of Socket-Template Scaffold System without XBracing," J. Perform. Constr. Facil., vol. 34, no. 1, pp. 1-14, 2020

[10] E. Blazik-Browa, J. Bec, A. Robak, J. Szulej, and I. Szer, "Technical Factors Affecting Safety on A Scaffolding," Towar. better Safety, Heal. Wellbeing, Life Constr., pp. 154-163, 2015

[11] J. L. Peng, S. L. Chan, and C. L. Wu, "Effects of geometrical shape and incremental loads on scaffold systems," J. Constr. Steel Res., vol. 63, no. 4, pp. 448-459, 2007

[12] A. Y. T. Chu, S. L. Chan, and K. F. Chung, "Stability of modular steels scaffolding systems - Theory and verification," Adv. Build. Technol., vol. 1, no. 1977, pp. 621-628, 2002

[13] R. Lacalle, S. Cicero, D. Ferreño, and J. A. Álvarez, "Failure analysis of a bolt in a scaffolding system," Eng. Fail. Anal., vol. 15, no. 3, pp. 237-246, 2008

[14] L. B. Weesner and H. L. Jones, "Experimental and analytical capacity of frame scaffolding," Eng. Struct., vol. 23, no. 6, pp. 592-599, 2001

[15] H. Takahashi, K. Ohdo, and S. Takanashi, "Experimental study and evaluation method for the buckling strength of scaffold," Procedia Eng., vol. 14, pp. 297-303, 2011

[16] B. Milojkovic, R. G. Beale, and M. H. R. Godley, "Determination of the factors of safety of standard scaffold structures," Adv. Steel Struct., vol. I, pp. 303-310, 2002

[17] M. I. Rokhim, M. S. Yob, O. J. O. Kurdi, and M. M. Izahar, "Validated Finite Element Model Of Build-Up IBeam Using Triangular Element Under 4-Point Bending Load,” Int. J. Mech. Prod. Eng. Res. Dev., vol. 10, no. 3, pp. 14593-14600, 2020

[18] M. S. Yob, R. Junaidi, N. A. Mat Tahir, O. Kurdi, and M. J. Abd Latif, "Validated Finite Element Model Of Build-Up I-Beam Using Triangular Element Under 4-Point Bending Load,” J. Mech. Eng. Technol., vol. 12, no. 2, pp. 46-53, 2020

[19] M. Pienko, A. Robak, E. Blazik-Borowa, and J. Szer, "Safety Conditions Analysis of Scaffolding on Construction Sites," Int. J. Civ. Environ. Eng., vol. 12, pp. 72-77, 2018

[20] F. J. Forteza, J. M. Carretero-Gómez, and A. Sesé, "Occupational risks, accidents on sites and economic performance of construction firms," Saf. Sci., vol. 94, pp. 61-76, 2017

[21] J. C. Rubio-Romero, M. Carmen Rubio Gámez, and J. A. Carrillo-Castrillo, “Analysis of the safety conditions of scaffolding on construction sites," Saf. Sci., vol. 55, pp. 160-164, 2013

[22] BS1139-5, "Metal scaffolding - Part 5: Specification for materials, dimensions, design loads and safety requirements for service and working scaffolds made of prefabricated elements," 1990 
[23] MS1462-1, "MS 1462-2-1:2010 etal scaffolding - Part 2 Tubular (tube and coupler) scaffolds - Section 1 Specification for steel tubes," 2015

[24] MS1462-2, "MALAYSIAN STANDARD Metal scaffolding - Part 2 Tubular (tube and coupler) scaffolds Section 3 Specification for steel and aluminium couplers, fitting and accessories," 2015

[25] MS1462-2, "Metal scaffolding - Part 2 : Tubular ( Tube and Coupler Scaffolds)," 2010

[26] BS1139-1, "Metal scaffolding - Part 1: Tubes Section 1.1 Specification for Steel Tube," 1990

[27] BS1139-1, "Metal scaffolding - Part 1: Tubes Section 1.2 Specification for Aluminium Tube," 1990 